\title{
What If All Patients with Breast Cancer in Malaysia Have Access to the Best Available Care: How Many Deaths Are Avoidable?
}

\author{
G. F. Ho ${ }^{1}$, N. A. Taib ${ }^{1}$, R. K. Pritam Singh ${ }^{2}$, C. H. Yip ${ }^{3}$, M. M. Abdullah ${ }^{3} \&$ T. O. Lim ${ }^{4}$ \\ ${ }^{1}$ Faculty of Medicine University of Malaya, Malaysia \\ ${ }^{2}$ Together Against Cancer Association, Malaysia \\ ${ }^{3}$ Subang Jaya Medical Centre, Malaysia \\ ${ }^{4}$ ClinResearch SB, Malaysia \\ Correspondence: Dr Lim TO, ClinResearch, D7-3-1 (1st Floor) Block D7, Pusat Perdagangan Dana 1, Jalan PJU \\ 1A/46, 47301 Petaling Jaya, Selangor Darul Ehsan, Malaysia
}

Received: March 25, 2017 Accepted: April 26, 2017 Online Published: May 8, 2017

doi:10.5539/gjhs.v9n8p32 URL: https://doi.org/10.5539/gjhs.v9n8p32

\begin{abstract}
Background: Cancer is a leading cause of death in the world and the fourth leading cause in Malaysia. A widening disparity in cancer burden has emerged between high and low-middle income countries. A similar disparity due to differential access to cancer care between affluent and deprived groups is likely to exist within developing country too. We assess this inequality by estimating the number of deaths due to cancer that would be avoidable if all patients had access to the best available care in Malaysia, a high middle income country.

Methods: The number of avoidable deaths is the difference between the number of deaths estimated by GLOBOCAN12 for Malaysia (which is consistent with published estimates on cancer survival), and the expected number of deaths if all patients with Breast Cancer (BC) had experienced the age-ethnic-stage specific survival outcomes observed in a leading private cancer centre in Malaysia. Data on age-ethnic-stage composition of the general BC population were from local cancer registry and public hospitals providing safety net cancer services.
\end{abstract}

Findings: Of the 2312 excess deaths due to BC, 2048 (88\%) were avoidable. Of these avoidable deaths, 1167 (57\%) were attributable to late stage presentation while $881(43 \%)$ were due to lack of access to optimal treatment. Sensitivity analyses however show that the $88 \%$ avoidable deaths may be as low as $50 \%$, taking into account differences in socio-economic status, over-diagnosis and lack of very long term survival data.

Interpretation: The huge number of avoidable deaths highlights the high cancer mortality rate among the deprived and the vast disparity in access to cancer care between the rich and poor within Malaysia, which mirrors the global cancer divide between rich and poor countries.

Cancer care system that deliver such disastrous and inequitable outcomes is clearly under-performing. It is in urgent need of reform.

Keywords: breast cancer, cancer burden, avoidable deaths, inequality, disparity, health policy, health system, developing country

\section{Introduction}

Cancer is a leading cause of premature death in the world and ranks fourth, after Cardiac \& Circulatory diseases, Infection and Injury, as a cause of premature death in Malaysia. A widening disparity in cancer burden has emerged between high income and low-middle income countries (LMIC) (Global Task Force on Expanded Access to Cancer Care and Control in Developing Countries, 2011, Global Task Force on Expanded Access to Cancer Care and Control in Developing Countriesc, 2010). In 2008, LMIC accounted for 56\% of all cancers (Boyle, 2008) and two-thirds of the 7.6 million deaths every year from cancer worldwide occur in LMIC (Beaulieu, 2010; Ferlay, 2010). This is due to improving survival in developed countries in the past decades as a result of earlier detection and new and more effective treatments (Jemal, 2008), but little of these advances are accessible to most people in LMIC. Closing this cancer divide between rich and poor countries is not just an ethical imperative. There is also sound economic justification for reducing avoidable cancer deaths.

It appears however that even in relatively wealthy high middle income country such as Malaysia, access to cancer services is limited ( $\mathrm{Lim}, 2014)$, and cancer mortality rate is unconscionably high. GLOBOCAN12 
recently reported a Mortality: Incidence ratio of $60 \%$ for Malaysia (International Agency for Research on Cancer, 2013). This neglect of cancer care in Malaysia has resulted in individual patients to seek care when they could afford it, thus creating a natural experiment to investigate the mortality impact of differential access to care in this population. On this basis, we estimate the number of deaths due to cancer that would be avoidable if all Malaysian patients had access to the best available care in the country.

\section{Methods}

This study is based entirely on secondary data sources available on cancer in Malaysia. The Ministry of Health's Medical and Research Ethics Committee approved the study. The number of avoidable deaths is the difference between the number of cancer deaths estimated for the general population in Malaysia and the expected number of deaths if all cancer patients had experienced the age-ethnic and stage specific survival outcomes observed in a reference population in Malaysia.

Data on the distribution of cancer incidence and mortality by patients' demographics and cancer stages are scarce in developing countries including Malaysia (Coleman, 2010). Only breast cancer (BC) is relatively rich in data, hence we could only use data on this cancer to estimate the number of avoidable BC deaths.

\subsection{Sources of Data on BC in the General Population}

Data on the age-ethnic composition and cancer stage distribution of the general BC population is available from the national registry (NCR) (Zainal, 2011) though there is considerable under-reporting. Drugs utilization data (IMS pharmaceutical audits 2012) anti-cancer hormonal drugs (ATC L02B1 Anti-eostrogen and L02B3 Aromatase inhibitors) showed that $74 \%$ of patients were treated in safety net public hospitals in 2012 . In the absence of national data, we therefore use multiple data sources that include patients predominantly from public hospitals to derive the age-race-stage distribution of $\mathrm{BC}$ in the general population.

1) National Cancer Registry data (Zainal, 2011), which last reported on cancer incidence in 2007.

2) Penang Cancer Registry data (a regional registry) (Azizah, 2010), which last reported on cancer incidence in 2004 to 2008, and on survival outcome in year 2005 to 2009 (Allemani, 2014).

3) A population based study (Abdullah, 2013) on BC survival outcome. The study combined data from both the national registry and a hospital discharge database (data mostly from public hospitals) in 2000 to 2005.

4) A single large public hospital based study (Ibrahim, 2012) on BC survival outcome in 2005 to 2009.

5) A single academic centre based study (Saxena, 2016) on BC survival outcome in 1993 to 2007.

6) A breast cancer cohort study which enrolled patients from 8 public and private hospitals in 2011 to 2012 (Jemal 2008). Only data on patients from public hospitals are used.

There is also no data on the mortality outcome in the general population with BC. Survival data were available from source (2), (3) and (4) above. Globocan 2012 (International Agency for Research on Cancer, 2013) also reported a Mortality: Incidence ratio of 0.49 for $\mathrm{BC}$ in Malaysia.

\subsection{Source of Data on the Reference Population}

The reference population selected for this study is the patients treated at the only leading cancer centre in Malaysia which could accomplish survival outcome comparable to those observed in leading centres in developed countries (Healthcare Performance Measurement \& Reporting for SJMC's Breast Cancer care services, 2016). This reference population consisted of Malaysian women with pathologically confirmed primary breast cancer treated at the centre between 2008 and 2012. Cases were identified through the hospital register as well as operative surgery and treatment records. Case ascertainment was independently verified to be complete. A rigorous procedure was followed to ensure complete ascertainment of mortality as follows:

1) All cases were linked through their names and identity card number to the national mortality database from the National Registration Department (to whom all deaths occurring in the country must be reported by law) to ascertain mortality outcome. This was performed in 2013 and repeated in 2014.

2) Remaining cases of uncertain outcome were linked through their names and hospital number to the hospital register (which record all visits). Patients who had a visit after 31 Dec 2013 are considered alive.

3) A sample of the remaining cases with Stage I or II cancers, and $100 \%$ of cases with Stage III or IV cancers, were contacted by phone to enquire about the patients' status. All patients with Stage I were thus determined to be alive, one out of 32 with Stage II was dead, likewise 5 (12\%) out of 42 with Stage III and 2 (40\%) out of 6 with Stage IV. 
4) For survival analysis, we assume all cases with Stage I who were not contacted (60 cases) to be alive. For the 43 case with Stage II, we randomly select one case and impute her outcome as death. We assume all remaining uncontacted patients with Stage III ( 6 cases) and IV ( 1 case) cancers to be dead. Thus, any bias in the survival estimates arising of missing information on mortality outcome is conservative.

\subsection{Statistical Methods}

The observed number of deaths in a population with $\mathrm{BC}$ has 2 components:

(1) Background population mortality. This is the number of deaths that would be expected if BC patients had experienced only the background mortality (all-cause death rates) of the general population of the same age, sex, race. This is estimated from the population lifetable (Department of Statistics, Malaysia 2013).

(2) Excess deaths attributable to cancer, which is the difference between the observed number of deaths and background mortality.

Avoidable deaths is the difference between the excess deaths estimated above and the expected number of deaths despite best care. The latter is the number of deaths that would occur if $\mathrm{BC}$ patients had experienced the age-race specific patient survival rates of the reference center providing best available care in the country.

The expected number of deaths despite best care is estimated using the formula below (Frank, 2010):

$\mathrm{M}=\Sigma\left(\mathrm{I}_{\mathrm{ij}} *\left(1-\mathrm{S}_{\mathrm{ij}}\right)\right.$; where

$\mathrm{M}$ is number of deaths, sum over $\mathrm{i}$ and $\mathrm{j}$

$\mathrm{I}$ is $\mathrm{BC}$ incident count in age group $\mathrm{i}$ and race $\mathrm{j}$ in the general population.

$\mathrm{S}$ is $\mathrm{BC}$ survival probability in the reference center in age group $\mathrm{i}$ and race $\mathrm{j}$.

The estimated number of avoidable excess deaths in turn has 2 components:

(3) Avoidable deaths due to late presentation. As shown in Table 1, 42\% of patients with $\mathrm{BC}$ in the general population presented in Stage 3 or 4, in contrast only $27 \%$ of patients did in the reference centre. We first estimate the number of deaths that would be expected if $\mathrm{BC}$ patients had experienced the age-race-stage specific patient survival rates of the reference center, which has a low proportion of patients presenting in late stages. This is estimated using the same formula above. This number minus the expected number of deaths despite best care (from (2) above) gives the number of avoidable deaths due to late presentation.

(4) Avoidable deaths due to lack of access to best available treatment. This is the difference between the number of avoidable excess deaths and the estimate (3) above.

Table 1. Summary of available data on Demographic and Tumor Characteristics of patients with Breast cancer in Malaysia

\begin{tabular}{|c|c|c|c|c|c|c|c|c|}
\hline $\begin{array}{l}\text { Patient } \\
\text { characteristics }\end{array}$ & $\begin{array}{l}\text { Data source, } \\
\text { Setting and year }\end{array}$ & $\begin{array}{l}\text { National } \\
\text { Cancer } \\
\text { Registry } \\
2007\end{array}$ & $\begin{array}{l}\text { Pinang } \\
\text { (regional) } \\
\text { Cancer } \\
\text { Registry } \\
\text { 2004-2008 }\end{array}$ & $\begin{array}{l}\text { National } \\
\text { Cancer } \\
\text { registry \& } \\
\text { Public } \\
\text { hospitals, } \\
2000 \text { to } 2005 \\
\end{array}$ & $\begin{array}{l}\text { Single } \\
\text { Public } \\
\text { hospital, } \\
\text { 2005-2009 }\end{array}$ & $\begin{array}{l}\text { BC } \\
\text { cohort, } \\
\text { public } \\
\text { hospital } \\
\text { data } \\
2011-2012\end{array}$ & $\begin{array}{l}\text { Single } \\
\text { academic } \\
\text { public } \\
\text { hospital, } \\
\text { 1993-2007 }\end{array}$ & $\begin{array}{l}\text { Reference } \\
\text { centre Single } \\
\text { private } \\
\text { hospital } 2008 \\
\text { to } 2012\end{array}$ \\
\hline $\begin{array}{l}\text { Number of } \\
\text { patients }\end{array}$ & $\begin{array}{l}\text { Number of } \\
\text { patients }\end{array}$ & 3242 & 1699 & 13,060 & 868 & 740 & 3320 & 675 \\
\hline \multirow[t]{3}{*}{ Age, years } & Mean & - & - & 51 & 51 & 54 & 50 (median) & 53 \\
\hline & $\%$ Age $<50$ & $43 \%$ & $35 \%$ & $49 \%$ & $44 \%$ & $35 \%$ & $46 \%$ & $36 \%$ \\
\hline & $\%$ Age $>=50$ & $57 \%$ & $65 \%$ & $51 \%$ & $56 \%$ & $65 \%$ & $54 \%$ & $64 \%$ \\
\hline \multirow[t]{3}{*}{ Race } & $\%$ Malay & $44 \%$ & $23 \%$ & $54 \%$ & $58 \%$ & $60 \%$ & $22 \%$ & $14 \%$ \\
\hline & $\%$ Chinese & $41 \%$ & $66 \%$ & $27 \%$ & $25 \%$ & $25 \%$ & $64 \%$ & $77 \%$ \\
\hline & $\begin{array}{l}\% \text { Indian \& } \\
\text { Others }\end{array}$ & $15 \%$ & $11 \%$ & $17 \%$ & $17 \%$ & $14 \%$ & $14 \%$ & $9 \%$ \\
\hline \multirow[t]{2}{*}{$\begin{array}{l}\text { Healthcare } \\
\text { financing }\end{array}$} & $\%$ Public & - & - & - & $100 \%$ & $100 \%$ & - & $0 \%$ \\
\hline & $\%$ & - & - & - & $0 \%$ & $0 \%$ & - & $85 \%$ \\
\hline
\end{tabular}




\begin{tabular}{|c|c|c|c|c|c|c|c|c|}
\hline & \multicolumn{8}{|l|}{ Out-of-pocket } \\
\hline & $\begin{array}{l}\text { \% Private } \\
\text { insurance }\end{array}$ & - & - & - & $0 \%$ & $0 \%$ & - & $9 \%$ \\
\hline & \% Employers & - & - & - & $0 \%$ & $0 \%$ & - & $6 \%$ \\
\hline \multirow[t]{4}{*}{ Cancer Stage } & $\%$ Stage I & $21 \%$ & $24 \%$ & - & $15 \%$ & $11 \%$ & $22 \%$ & $31 \%$ \\
\hline & $\%$ Stage II & $37 \%$ & $46 \%$ & - & $44 \%$ & $35 \%$ & $42 \%$ & $42 \%$ \\
\hline & $\%$ Stage III & $24 \%$ & $17 \%$ & - & $26 \%$ & $34 \%$ & $22 \%$ & $22 \%$ \\
\hline & $\%$ Stage IV & $18 \%$ & $13 \%$ & - & $16 \%$ & $21 \%$ & $11 \%$ & $5 \%$ \\
\hline \multirow[t]{4}{*}{ Biomarkers } & $\% \mathrm{ER}+$ or $\mathrm{PR}+$ & - & - & - & - & $68 \%$ & - & $73 \%$ \\
\hline & $\begin{array}{l}\% \text { HER2 ISH+ } \\
\text { or IHC }+\end{array}$ & - & - & - & - & $34 \%$ & - & $33 \%$ \\
\hline & $\begin{array}{l}\% \text { Triple } \\
\text { negative }\end{array}$ & - & - & - & - & $18 \%$ & - & $14 \%$ \\
\hline & $\begin{array}{l}\% \text { No } \\
\text { information }\end{array}$ & - & - & - & - & $40 \%$ & - & $18 \%$ \\
\hline
\end{tabular}

Table 2. Summary of available data on Breast cancer Mortality outcome in Malaysia

\begin{tabular}{|c|c|c|c|c|c|c|}
\hline Data source, Setting and year & $\begin{array}{l}\text { Pinang } \\
\text { (regional) } \\
\text { Cancer } \\
\text { Registry } \\
\text { 2005-2009 }\end{array}$ & $\begin{array}{l}\text { National } \\
\text { Cancer } \\
\text { registry \& } \\
\text { Public } \\
\text { hospitals, } \\
2000 \text { to } 2005\end{array}$ & $\begin{array}{l}\text { Single Public } \\
\text { hospital, } \\
\text { 2005-2009 }\end{array}$ & $\begin{array}{l}\text { Globocan } \\
2012\end{array}$ & $\begin{array}{l}\text { Single } \\
\text { academic } \\
\text { public } \\
\text { hospital, } \\
\text { 2001-2007 }\end{array}$ & $\begin{array}{l}\text { Reference } \\
\text { centre Single } \\
\text { private } \\
\text { hospital } 2008 \\
\text { to } 2012\end{array}$ \\
\hline Number of patients & 3803 & 13,060 & 868 & 5410 & 3325 & 675 \\
\hline Number of deaths & - & - & - & 2572 & - & - \\
\hline $\begin{array}{l}\text { Age standardized Mortality rate } \\
\text { per } 100,000 \text { population }\end{array}$ & - & - & - & 18.9 & - & - \\
\hline Mortality: Incidence Ratio & - & - & - & $49 \%$ & - & - \\
\hline Overall survival at 5-year & - & $49 \%$ & $44 \%$ & $51 \%$ & $73 \%$ & $85 \%$ \\
\hline $\begin{array}{l}\text { Age standardized Relative survival } \\
\text { at } 5 \text {-year }\end{array}$ & - & - & - & - & - & $88 \%$ \\
\hline $\begin{array}{l}\text { Age standardized Net survival at } \\
5 \text {-year }\end{array}$ & $68 \%$ & - & - & - & - & $88 \%$ \\
\hline
\end{tabular}

The estimate of the number of avoidable deaths above is influenced mainly by the estimate of expected deaths, which in turn is likely to be under-estimated, and thus inflating the number of avoidable deaths, for three reasons. One, we could not adjust for the differences in socio-economic status (SES) between the reference population ( $85 \%$ of whom could afford to finance their own cancer treatment) and the general population (poorer patients treated in safety net public hospitals) on account of lack of data on SES for both BC patients and the background population. SES is a strong predictor of cancer survival outcomes (Woods, 2006; Ellis, 2012; Pokhrel, 2010). Two, over-diagnosis due to intensive low value screening (Wilt, Harris, \& Qaseem, 2015) is likely to be common in the reference population. This is well documented in other Asian country (Ahn, 2014) where cancer screening services are over-sold to an affluent population. Both these factors account to an unknown extent for the very high survival outcome among patients treated at the reference centre, which reported a relative survival for patients with Stage $1 \mathrm{BC}$ that is better $(>100 \%)$ than the background population without BC (Healthcare Performance Measurement \& Reporting for SJMC's Breast Cancer care services, 2016). Three, the patient survival probability in the reference population should be estimated over a suitably long duration when most deaths would have occurred. Unfortunately, only data on survival up to 5 years are available, and no doubt many of the patients with Stage 3 and $4 \mathrm{BC}$ would have gone on to die between 5 and 10 years after diagnosis. 
Unpublished data from a single academic centre confirms this. At 10 years after diagnosis, patient survival is practically zero for stage $4 \mathrm{BC}$ but about $40 \%$ for stage 3 .

We conduct sensitivity analyses to assess the magnitude of the over-estimate. We randomly remove $20 \%$ of subjects who are likely to contribute to this bias due to the first and second reason above. For this purpose, we use out-of-pocket financing as a proxy indicator of SES status and Stage 1 status for over-diagnosis. For the third contributor to the bias, we randomly assume 30 patients with Stage 3 BC were dead (resulting in $25 \%$ survival at 5 years). This is conservative as this outcome is worse than unpublished data on 10 years' survival from a single centre (see above). We also assume all patients with stage $4 \mathrm{BC}$ were dead. Excess mortality after 5 years for patients with State 1 and 2 BC were negligible since their reported relative survival exceeded or were near $100 \%$ at 5 years after diagnosis

\section{Results}

The demographic and tumor characteristics of $\mathrm{BC}$ reported by various data sources and on the reference population are summarized in Table 1. The age distribution was comparable among all populations. The reference population, a leading private cancer centre, was mainly Chinese (76\%) who financed their cancer care largely out-of-pocket $(85 \%)$ and presented predominantly in Stage I or II, in sharp contrast to the other populations. Biomarkers were also poorly characterized in the other populations.

Table 2 summarizes the mortality outcomes of BC patients in Malaysia reported by the various sources. Not surprisingly, patients treated at the reference centre have excellent survival outcome, which was the reason for its selection as the reference centre for this study. The survival outcomes reported by various individual studies, which is more representative of the general BC patients' experiences, were poorer. The survival outcomes of study populations that included patients predominantly from public hospitals were poor and consistent with the mortality rate reported by GLOBOCAN12. The number of BC deaths reported by GLOBOCAN12 (2572) was therefore used as the observed number of deaths in this study.

Table 3 summarizes the estimates of the annual number (\%) of excess deaths. $88 \%$ of these deaths are avoidable. Sensitivity analyses however show that this percentage may be as low as $50 \%$, taking into account differences in SES, over-diagnosis and lack of long term survival data. Of the 2048 avoidable deaths, $1167(57 \%)$ were attributable to late presentation and $881(43 \%)$ due to lack of access to treatments.

Table 3. Annual number (\%) of deaths that would be avoidable if all patients with Breast Cancer have access to the best available care in Malaysia

\begin{tabular}{|c|c|}
\hline Estimates & Results \\
\hline Observed number of $\mathrm{BC}$ deaths $\left(\mathrm{M}_{\mathrm{obs}}\right)$ reported by Globacan 2012 & 2572 \\
\hline 1. Estimated number of deaths due to background population mortality* & 260 \\
\hline 2. Estimated number of Excess deaths & $2312(100 \%)$ \\
\hline Estimated number (\%) of excess deaths despite best care & $264(12 \%)$ \\
\hline Estimated number (\%) of excess deaths that would be avoidable & $2048(88 \%)$ \\
\hline Estimated number of Avoidable excess deaths & $2048(100 \%)$ \\
\hline 1. Number (\%) attributed to Lack of early diagnosis & $1167(57 \%)$ \\
\hline 2. Number (\%) attributed to Lack of treatment & $881(43 \%)$ \\
\hline
\end{tabular}




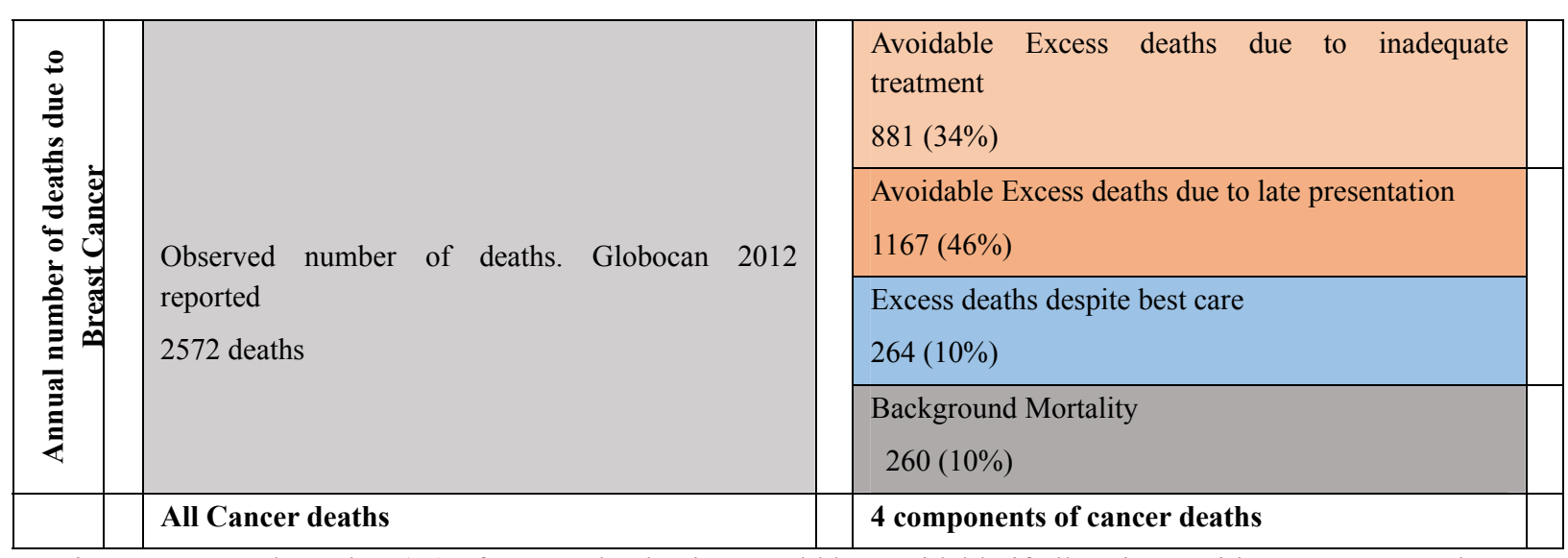

Figure 1. Annual number (\%) of excess deaths that would be avoidable if all patients with Breast Cancer have access to the best available care in Malaysia

\section{Discussion}

Breast cancer is a common disease across the world but outcomes vary significantly between high and low income countries. Most women diagnosed with breast cancer in high-income countries can reasonably expect to be cured and enjoy a long life expectancy. Such progress has been made possible by high performing health services able to translate the advances in cancer screening and treatments into improved outcomes. However, in LMIC, under-resourced and under-performing health services continue to fail to deliver adequate screening and treatments leading to poor outcomes. It is well known that developing countries bore a disproportionate share of cancer deaths worldwide (Beaulieu 2009, Ferlay 2010). We have shown in this study that much of these deaths are avoidable, the number could range from 50 to $88 \%$ of cancer deaths. And these deaths are about equally attributable to late presentation and lack of access to optimal treatment.

Estimate of cancer survival is scarce from developing countries, and often unreliable due to incomplete case ascertainment and follow up leading to inflation of survival estimates (Coleman, 2010). We avoided these pitfalls through independent verification of case ascertainment, through using a rigorous procedure to ensure complete follow-up and using conservative assumptions where missing data are unavoidable. We also estimate the magnitude of unavoidable bias through sensitivity analysis. The results lower the percentage of avoidable excess deaths from $88 \%$ to $50 \%$, which is still very high.

The large number of avoidable deaths found in this study is largely due to differential access to cancer care between the affluent and deprived groups. Other studies which estimate avoidable cancer deaths attributable to deprivation have found comparatively lower numbers. In England (Ellis, 2012), the percentage of avoidable BC deaths due to deficit in survival between rich and poor have declined from $27 \%$ in $1996-2000$ to $24 \%$ in 2004-2006. In Finland (Pokhrel, 2010), despite its equitable health system, the percentage of avoidable BC deaths (using educational background as proxy for SES) was $17 \%$. These comparisons highlight the huge disparity in access to cancer care and outcomes between the rich and poor within a developing country, which mirrors the global cancer divide between rich and poor countries. To minimize such extreme disparity, countries like UK and Finland have well-resourced and high-performing health services which are accessible to all, in contrast to the under-performing state-run safety net healthcare common in developing countries.

Cancer care services that deliver such poor outcome and such vast disparity between socio-economic groups in the same country are clearly under-performing. Health policy that specifically address these concerns barely exists. The same could probably be said for other health services except that there is hardly any data on disease epidemiology, health outcomes and services for most therapies in Malaysia. It would be too easy to attribute such poor performance to resource scarcity. Malaysia is a relatively wealthy high middle income country where much cancer care should be affordable. The cancer care system in Malaysia is in urgent need of reform.

\section{Acknowledgements}

We wish to thank all those whose names are not mentioned here who render their excellent service especially during the data collection.

\section{Conflict of Interest and Funding disclosure}

None of the authors have competing interests. This study is funded by research grants from Together Against 
Cancer Association and Ministry of Education Malaysia (High Impact Research Grant).

\section{References}

Abdullah, N. A., Mahiyuddin, W. R. W., Muhammad, N. A., Ali, Z. M., Ibrahim, L., Tamim, N. S. I., ... Kamaluddin, M. A. (2013). Survival Rate of Breast Cancer Patients In Malaysia: A Population-based Study. Asian Pac J Cancer Prev, 14, 4591-4594. https://doi.org/10.7314/APJCP.2013.14.8.4591

Ahn, H. S., Kim, H. J., \& Welch, H. G. (2014). Korea's Thyroid-Cancer "Epidemic"-Screening and Over-diagnosis. $N$ Engl J Med, 371(19), 1765-7X. https://doi.org/10.1056/NEJMp1409841

Allemani, C., Weir, H. K., Carreira, H., et al., and the CONCORD Working Group. (2014). Global surveillance of cancer survival 1995-2009: analysis of individual data for 25676887 patients from 279 population-based registries in 67 countries (CONCORD-2). Lancet, 2014. https://doi.org/10.1016/S0140-6736(14)62038-9

Azizah, A. M., Devaraj, T., Bina, R. S., Norbaiyah, Y., Nooraihan, M., \& Noorshila, S. (2010). Penang Cancer Registry Report 2004-2008, Penang State Health Department 2010.

Beaulieu, N., Bloom, D., Bloom, R., \& Stein, R. (2009). Breakaway: the global burden of cancer-challenges and opportunities. A report from the Economist Intelligence Unit, 2009. The Economist.

Boyle, P., \& Levin, B. (2008). World cancer report 2008. IARC Press, International Agency for Research on Cancer.

Coleman, M. P. (2010). Cancer survival in the developing world. The lancet oncology, 11(2), 110-111. https://doi.org/10.1016/S1470-2045(09)70371-7

Department of Statistics, Malaysia. Abridged Life Tables 2000-2011 Malaysia.

Ellis, L., Coleman, M. P., \& Rachet, B. (2012). How many deaths would be avoidable if socioeconomic inequalities in cancer survival in England were eliminated? A national population-based study, 1996-2006. European journal of cancer, 48(2), 270-278. https://doi.org/10.1016/j.ejca.2011.10.008

Farmer, P., Frenk, J., Knaul, F. M., Shulman, L. N., Alleyne, G., Armstrong, L., ... \& Gospodarowicz, M. (2010). Expansion of cancer care and control in countries of low and middle income: a call to action. The Lancet, 376(9747), 1186-1193. https://doi.org/10.1016/S0140-6736(10)61152-X

Lichtenberg, F. R. (2010). Are Increasing 5-Year Survival Rates Evidence of Success Against Cancer?: A Reexamination Using Data from the US and Australia (No. w16051). National Bureau of Economic Research.

Global Task Force on Expanded Access to Cancer Care and Control in Developing Countries. Closing the cancer divide: a blueprint to expand access to low and middle income countries. Boston, MA: Harvard Global Equity Initiative, 2011.

Healthcare Performance Measurement \& Reporting for SJMC's Breast Cancer care services, Patient Survival outcome 2008 to 2012.Retrieved from http://www.hrms.com.my/hpmrs/page.jsp?content=pReports

Ibrahim, N. I., Dahlui, M., Aina, E. N., \& Al-Sadat, N. (2012). Who are the breast cancer survivors in Malaysia?. Asian Pacific Journal of Cancer Prevention, 13(5), 2213-2218. https://doi.org/10.7314/APJCP.2012.13.5.2213

IMS pharmaceutical audits report 2012.

International Agency for Research on Cancer, WHO. GLOBOCAN 2012: Cancer incidence, mortality, and prevalence worldwide in 2012. 2013. Retrieved from http://globocan.iarc.fr/

Jemal, A., Thun, M. J., Ries, L. A., Howe, H. L., Weir, H. K., Center, M. M., ... \& Ajani, U. A. (2008). Annual report to the nation on the status of cancer, 1975-2005, featuring trends in lung cancer, tobacco use, and tobacco control. Journal of the National Cancer Institute, 100(23), 1672-1694. https://doi.org/10.1093/jnci/djn389

Lim, G. C., Aina, E. N., Cheah, S. K., Ismail, F., Ho, G. F., Tho, L. M., ... \& Abdullah, M. M. (2014). Closing the global cancer divide-performance of breast cancer care services in a middle income developing country. $B M C$ cancer, 14(1), 212. https://doi.org/10.1186/1471-2407-14-212

Pokhrel, A., Martikainen, P., Pukkala, E., Rautalahti, M., Seppä, K., \& Hakulinen, T. (2010). Education, survival and avoidable deaths in cancer patients in Finland. British journal of cancer, 103(7), 1109-1114. https://doi.org/10.1038/sj.bjc.6605861 
Saxena, N., Hartman, M., Bhoo-Pathy, N., Lim, J. N., Aw, T. C., Iau, P., ... \& Verkooijen, H. M. (2012). Breast cancer in South East Asia: comparison of presentation and outcome between a middle income and a high income country. World journal of surgery, 36(12), 2838-2846. https://doi.org/10.1007/s00268-012-1746-2

Wilt, T. J., Harris, R. P., \& Qaseem, A. (2015). Screening for cancer: advice for high-value care from the American College of Physicians. Annals of internal medicine, 162(10), 718-725. https://doi.org/10.7326/M14-2326

Woods, L. M., Rachet, B., \& Coleman, M. P. (2006). Origins of socio-economic inequalities in cancer survival: a review. Annals of Oncology, 17(1), 5-19. https://doi.org/10.1093/annonc/mdj007

Zainal Ariffin, O., \& Nor Saleha, I. T. (2011). National cancer registry report 2007. Malaysia: Ministry of Health.

\section{Copyrights}

Copyright for this article is retained by the author(s), with first publication rights granted to the journal.

This is an open-access article distributed under the terms and conditions of the Creative Commons Attribution license (http://creativecommons.org/licenses/by/4.0/). 